\title{
Article
}

\section{A Subject of Concern: The Experiences of Social Workers Referred to the Health and Care Professions Council}

Worsley, Aidan Richard clive, McLaughlin, Kenneth and Leigh, Jadwiga

Available at http://clok.uclan.ac.uk/17966/

Worsley, Aidan Richard clive ORCID: 0000-0002-3925-3297, McLaughlin, Kenneth and Leigh, Jadwiga (2017) A Subject of Concern: The Experiences of Social Workers Referred to the Health and Care Professions Council. The British Journal of Social Work . ISSN 0045-3102

It is advisable to refer to the publisher's version if you intend to cite from the work. http://dx.doi.org/10.1093/bjsw/bcx005

For more information about UCLan's research in this area go to http://www.uclan.ac.uk/researchgroups/ and search for <name of research Group>.

For information about Research generally at UCLan please go to http://www.uclan.ac.uk/research/

All outputs in CLoK are protected by Intellectual Property Rights law, including Copyright law. Copyright, IPR and Moral Rights for the works on this site are retained by the individual authors and/or other copyright owners. Terms and conditions for use of this material are defined in the policies page.

\section{CLoK}

Central Lancashire online Knowledge www.clok.uclan.ac.uk

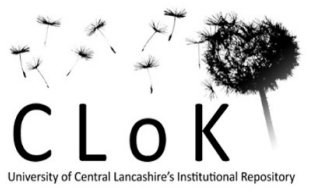


A Subject of Concern: The experiences of social workers referred to the Health and Care Professions Council

\section{Abstract}

In order to practise social work in England, all social workers must register with the Health and Care Professions Council (HCPC). Only those who are registered can legally work as or call themselves a social worker. Once registered, if concerns about their practice are raised social workers may find they are then made subject to a fitness to practise process. This article reports on the findings from interviews with social workers who were referred to the HCPC for practice issues. Our rationale was to hear and report on the lived experience of those going through the investigatory process. We carried out semi-structured interviews with eight social workers and used thematic analysis to analyse our data. The three main themes to emerge from our findings were organisational issues; representation and cost; and emotional toll. This paper discusses these findings in detail. We suggest that the current regulatory system situates social workers in a position of disadvantage during the Fitness to Practise process, and conclude by making a number of recommendations for consideration if future changes are to be made to the social work regulatory process.

\section{$\underline{\text { Introduction }}$}

In this paper we analyse data from interviews with social workers who have been subject to referral to the Health and Care Professions Council (HCPC) due to concerns being raised over their fitness to practise. The HCPC is the body responsible for the registration and regulation of social workers in England. The grounds for a referral are not explicitly defined but must be related to concerns over a registrant's 'fitness to practice'. The referral can come from any individual person or organisation. Much has been written about the regulation of social work from the perspectives of various other interested parties such as policy makers, academics, journalists and, albeit it to a lesser extent, social workers themselves (e.g. Authors 2015; Narey, 2014; Schraer, 2014). However, little consideration has been given to the effect a referral to the HCPC has on the individual social worker. It was this gap in the literature which prompted us to carry out the research on which this paper is based.

Our criteria for selecting social workers for interview focused on cases which related to either practice issues (such as workload or competence), as opposed to more personal and/or criminal issues such as drugs, alcohol or fraud. This is because we wanted to explore whether there were any themes linked to organisational or structural concerns, both with regard to workplace issues in terms of reasons for the referral to the HCPC and also issues experienced within the HCPC process itself. In this respect, whilst we cannot testify to the complete accuracy of the respondents' claims or recollections, it is their narratives and experiences we wished to highlight.

The remit of the HCPC is to protect the public and in order to do so it keeps a register of health and care professionals who it deems meet its professional standards in terms of training, professional skills, behaviour and health. Only those on its register are legally entitled to call themselves by their professional title. For example, it is illegal for anyone not 
on the HCPC register to call themselves a social worker (HCPC, 2012a). A registered professional who has concerns raised over their ability to meet the HCPC standards can be called before a 'Fitness to Practise' (FTP) hearing where the ultimate sanction could be that the individual's registration is removed. Such a sanction has severe implications for the social worker as it means they can no longer work as, or even refer to themselves as, a social worker. In determining whether professionals are fit to practise the HCPC uses the civil standard of proof when deciding the outcome of its FTP hearings. The decision therefore rests on the balance of probabilities rather than the higher criminal proceedings standard of beyond reasonable doubt (HCPC, 2012b).

Initial concerns relating to the conduct of the referred social worker are discussed by the HCPC's Investigating Committee. If members of that committee decide there is a case to answer the HCPC is obliged to proceed with the case to a final hearing. At this stage the complaint can still be deemed as 'not well founded'. Therefore, even if an allegation is substantiated it does not necessarily mean that the practitioner will be deemed unfit to practise.

If the FTP panel decide at the final hearing that the concerns raised do impair a registrant's fitness to practise a range of sanctions can be imposed. Article 29 of the Health and Social Work Professions Order (2001) states that those sanctions are: mediation; caution; conditions of practice; suspension; striking off (HCPC, 2011).

Protecting the public from social workers who are unfit to practise is undoubtedly a worthy endeavour. However, concerns have been raised that individual social workers could be held accountable for failings that are ultimately rooted in more systemic or organisational problems such as high caseloads, inadequate resources and poor staff supervision (Leigh, 2014). For example, the primary focus of the HCPC proceedings is on the action and behaviour of the individual social worker. This can be contrasted, for example, with serious case inquiries which whilst they provide a narrative and moral judgement about the conduct of professionals they also consider organisational factors that may have affected practice (Furness, 2015).

There is little national quantitative guidance on appropriate workload levels for social workers. The 'Standards for Employers of Social Workers in England' (LGA 2014) talk generically about 'safe and manageable' workloads that are allocated transparently, include an awareness of complexity and indeed, that employers publish data on average caseloads. The Standards are more specific with supervision and talk of monthly contact - with weekly sessions for NQSWs in the first few weeks of practice.

This raises an important issue in that some of the referrals made may be related, at least in part, to wider organisational problems rather than the sole failings of a social worker. This anomaly prompted our research as we were concerned that individual social workers could be held accountable for the systemic problems already present in their employing organisations.

In the sections that follow we explain the methods we undertook to gather data from our participants as well as the techniques used to analyse the interviews. We will then discuss 
and analyse those findings before concluding and making a number of recommendations in relation to the future of social work regulation.

\section{Methodology}

This project received initial ethical approval from the University of Central Lancashire. It was a three-part study which encompassed different areas of focus relating to the HCPC's Fitness to Practise process (Authors, 2015; Authors 2016 forthcoming). The aim of this part of the project focused on gathering and analysing data collected from a series of semistructured interviews conducted with eight qualified social workers, all of whom had been subject to the HCPC process for professional misconduct.

Participants were recruited through an online advert posted on the website of Community Care. Those who were interested in taking part were encouraged to contact one of the authors directly by email. In total twenty-eight people contacted us expressing an interest in taking part, however only twelve responded to the email subsequently sent with the participant information sheet which outlined our criteria. From these twelve, eight took part (two had been referred to the HCPC but had not yet been through the HCPC process and so did not meet our criteria, whilst the other two had not been referred to the HCPC process for organisational issues and so again did not meet our criteria). Participants were able to choose to be interviewed by telephone or face-to-face, with four opting for the former and four the latter. Whilst this difference is important in terms of interviewer/interviewee interaction it is important to note that we only analysed transcripts, not observational data. Only one of us conducted any given interview meaning that that two of us had never spoken to each (doesn't make sense this part- perhaps 'meaning that the other two did not'?) participant. For confidentiality reasons, all names have been changed in this paper. Interviews were recorded and then transcribed - the analysis and presentation of that data form the central body of this article.

Of the eight social workers we interviewed three were found to have No case to answer/No further action, a further three received either a caution/warning/or conditions of practice, and two were struck off the HCPC register. By way of comparison, the HCPC 2015 Annual Fitness to Practice report shows that of the 155 cases where social workers were taken before a FTP hearing that year ( $1^{\text {st }}$ April $2014-31^{\text {st }}$ March 2015) approximately $25 \%$ received a caution or conditions of practice, $32 \%$ had no further action/no case to answer and $43 \%$ were either struck off or suspended (HCPC, 2015).

The research drew heavily on a narrative approach, forming from 'an interest in biographical particulars as narrated by the ones who live them' (Chase, 2008:58). Narratives are usually concerned with the temporal nature of the data (in this case the journey over time through the HCPC proceedings) and the symbolic meaning they offer (Bryman, 2004). Elliot (2005) notes other common themes of a narrative approach: a desire to empower participants, an interest in self and representation of self and an awareness that the researcher is also a narrator. We are conscious of the limitations of the narrative approach in seeing a rounded picture; we do not present, for example, narratives of managers or HCPC panel members but this was a deliberate choice for us. We are employing narratives in this singular way to 
combat a reductive tendency for those social workers to be reduced to their professional 'offences'. In this way we overtly seek allow a space that affords a 'narrative of resistance' from the respondents (Mishler, 2005: 432).

Once the interviews were completed, the transcriptions were each analysed by the authors independently and subjected to a broad, thematic analysis from within a grounded theory approach (Corbin \& Strauss, 2008; Braun \& Clarke, 2006). Memos and codes were applied to the data. We then met together as a group and discussed the key themes that had emerged. The analytic files of coded data were then arranged into a conceptually clustered (thematic) matrix (Robson 1998). A limitation of this process is that it is open to subjective bias. For this reason we wish to explicitly note that we have selected the chosen quotes in two general ways; some have been used selectively to underpin an argument and others are more illustrative of a sentiment expressed more generally across what is a relatively small sample (Holliday, 2007). The initial draft of the paper was then sent out to our participants (using pseudonyms) for comment and to ensure we had conveyed their testimonies as accurately as possible. Only one requested changes. This was in regards to the costs of an appeal to the High Court which we subsequently included.

In the next section, we examine and contextualise some extracts from the interviews we carried out.

\section{Findings}

The three main themes to emerge from the data were organisational issues; representation and cost; and emotional toll. We will discuss all three themes in detail before drawing our analysis together in the discussion section.

\section{Organisational Issues}

\section{Conflict with management}

All of our participants had experienced conflict with management for various reasons. The first two extracts provide an example of how this conflict materialised for two of our participants. Ann, an assistant team manager, left a Local Authority that she had worked for after disagreeing with her own manager over management techniques. From Ann's perspective, all had been going well until she was promoted and attended a management course. It was when she attended the course that she realised there were alternative ways in which a team could be supported, ways which differed from the one her own manager implemented:

...I'm a lot more of a nurturing kind of person, she was a lot more authoritarian, you did this and you do it by, whereas I tend to sit with somebody and do it with them....and so there was a big divide developing between the two of us, I couldn't work in the same way as she did...I was so unhappy I gave my notice in.... (Ann). 
It was not long after her departure that Ann received a notice that she was being disciplined for breaching certain codes of conduct. Despite having resigned from the authority of her own accord, Ann learned that she was being referred to the HCPC over a range of issues she was not informed were a problem at the time.

With Linda, problems began when a new manager joined a team that she had been working in for ten years. Linda informed us that part of her weekly hours included working on another project within the same Local Authority. This entailed visiting different groups within the community to explain what social care involved. Although Linda thoroughly enjoyed this aspect of her work, it also meant that she was not fully available for the work she was contracted to do with her team, something that she said appeared to annoy her new manager.

One day Linda came into work and found that the manager had ripped everything that had belonged to the team off the walls:

I said "What have you done that for?" He said "I'll speak to you in your next supervision". I said "That's a team issue, it's not for me in supervision"...and he came and stood over me...it was frightening...and he started shouting at me. I tried to leave but he blocked me at the door and he said..."You leave here without finding someone to cover your shift and you know the consequences".... I got in my car and broke down... there was a black mark against me after that and that's when the trouble all started.... (Linda).

Following this incident Linda was signed off sick with stress for three months. On her first day back at work she learned that her manager had referred her to the HCPC for practice issues. What most distressed Linda was the way in which her return to work had been handled. Rather than try and repair their differences, she felt she was being further punished by her manager as he presented her with a range of complaints from other professionals that she had not been aware of previously.

Despite having significant social work experience and both having worked for their respective authorities for long periods of time, both Ann and Linda felt that little attempt to resolve the conflict internally was made. Instead, both participants were of the view that the HCPC was used as a means to discipline those who dared disagree with their manager.

\section{Practice issues}

All of our participants talked about having high, complex caseloads but only Florence and Megan felt that their caseload affected their ability to practise effectively. For Florence, it was when she joined a community mental health team as an agency worker that her problems began. She described the work as "manic". Within two weeks she had been allocated 34 "complex and challenging" cases and she found that she was not only struggling to keep up but was 'physically and mentally worn out'. One day Florence returned from a visit and was called into the office by her supervisor and manager and confronted for not keeping up to date with putting contacts on the computer: 
It just totally shocked me how they were with me. They, I did not get any eye contact from my supervisor.... I showed them that I had all the contacts written down and explained that I just needed time to put them on the system....the manager was passive aggressive... he was leaning forward towards me and was shaking these papers really close to my face and it was just really intimidating....he was really hostile and angry.... came out just totally flabbergasted (Florence).

Florence started to become suspicious when another manager from a different team approached her and apologised for the way in which the meeting was handled:

I was told "Watch your back, if you step out of line in any way, or if you cross him, he, he will, you know, will make you suffer basically, he will report you and get rid of you" [starts to cry]...so, I'm sorry, I, I, I just get so emotional about it still... (Florence).

In Megan's case, although she was actually in the role of a team manager, due to high turnover of staff and a high rate of referrals she found she was carrying out the work of social worker and manager. One day Megan was called into her manager's office:

I was told that I wasn't allowed to work on the emergency out of hours service anymore...I was suspended straightaway and they just said it was something to do with a referral so I wasn't given any details of what l'd done...I wasn't allowed to contact anybody...so I couldn't get any information initially....I was just left to go on my own and nobody, nobody even took my badge off me (Megan).

This sudden suspension from a job that she had been in for fourteen years left Megan feeling completely "devastated". In addition, she was unclear of what it was she was supposed to have done. It was not until she received a letter from the HCPC that she learned she had been suspended for gross misconduct. However, although the HCPC did provide information of what the process would entail, no details of what constituted the 'gross misconduct' were provided which meant Ann was still no wiser about the nature of the referral. If an accurate account this is certainly contrary to the ACAS guidance on disciplinary process (ACAS, 2015).

\section{Cultural incongruence}

The extracts that have been presented so far have all implicitly or explicitly highlighted that, irrespective of the initial concerns, our respondents felt that organisational cultural practices helped exacerbate the situation. The following extracts may shed light on how this form of incongruence can take place and how two participants actually used the HCPC process to help them tackle issues with their organisation.

Daniel informed us that he had been working as a registered manager of a children's home when his local authority received an 'inadequate' Ofsted inspection. It was shortly after this announcement that his troubles began: 
The new Director came in with a 'you do it my way or get out' attitude and rather than putting in development for staff, everyone just went straight down the disciplinary route...at one point we had 64 social workers on disciplinarys...it was definitely a cultural thing (Daniel).

A team of social care investigators was employed to undertake an investigation and part of the process was to interview individual social workers to find out if they were aware of any 'bad practice'. Daniel found this approach threatening because of the way in which questions were posed:

If you knew about something and hadn't disclosed it they'd say, you know, 'We will come back for you and we will have you for collusion'.....(Daniel).

This intimidating approach apparently frightened many practitioners into telling investigators anything that had the potential to be of concern. One of Daniel's team disclosed concerns about a child who may have been at risk of sexual exploitation. Rather than investigate the allegation properly the information was turned immediately into a high-risk concern and Daniel was disciplined. Daniel however was sure he had not done anything wrong:

The local authority process was flawed...so I had a quick look on the HCPC website at what I needed to do in the event of disciplinary investigation and....I thought 'Ooh actually I need to self-refer here' because the local authority should have done it but hadn't (Daniel).

Daniel was allocated a case worker by the HCPC who contacted the organisation for further details but the organisation did not respond. Daniel sent through all the relevant information as requested and learned, a year later, that there would be 'no further action'. During that time Daniel found out that he had been exonerated by his agency but when he tried to return to his original post he could not because the post had already been filled. He received a substantial financial compensatory pay out as a result.

Liam was a reviewing officer for a local authority. For him, it was a difference in ideological perspectives that led him and his organisation to disagree. This resulted in a deterioration in communication between the two parties which led to a break down in trust, especially when the organisation raised issues about the way in which Liam practised:

...an integral part of my practice was.... I would rather not do anything than do something for the sake of being seen to do something, and the consequence of that was I would sort of hold the risk longer than other people...this terrified the hell out of senior managers, erm, and consequently when it all kicked off I just knew that I was toast....(Liam).

Like Daniel, Liam also knew that he would be unable to tackle the issues he had with his organisation alone and so he was pleased to be given the opportunity to go through the HCPC process. He felt the hearing would help him redress and challenge the organisation's concerns about his practice. 


\section{$\underline{\text { Representation and Cost }}$}

Previous research into professional regulatory hearings have noted the benefits of legal representation in achieving a favourable outcome/less severe sanction for registrants facing misconduct/fitness to practise concerns (McLaughlin, 2010; HCPC, 2015). However, this can be a costly endeavour with three of our participants spending between $£ 5000-£ 15,000$ on legal fees.

What we learned from our interviews is that it is not only legal fees that mitigate against the social worker having a 'fair' hearing. Participants informed us that the HCPC pays for the expenses of all its witnesses, including travel and accommodation. Yet those who agree to be a witness or character reference for the registrant must fund themselves. In addition, most hearings are in London which can make travel costs more expensive for those further away. We learned that it is not uncommon for proceedings to overrun, with witnesses being told they need to return the following day. Such circumstances can incur substantial additional costs in terms of lost wages, hotel, transport and meal costs as well as personal difficulties in terms of familial and/or other responsibilities.

The legal costs, combined with the drawn out process of the FTP procedure, can induce feelings of being beaten down over a lengthy period and we were informed that some of our participants did not engage, or more precisely, stopped engaging, with the HCPC simply because they could no longer afford to. For Amal, a previous referral to the GSCC took three years to complete and concluded with a twelve month admonishment. Later in her career, when another referral was made to the HCPC, it took two years to complete. It concluded with her being struck off the social work register, an outcome she believed occurred because she did not attend her hearing. Amal had had legal representation initially but because she was out of work she 'couldn't afford to keep paying the fees' so she dropped the legal representation. Because she felt she would not win without it, she eventually stopped going to the hearings:

It was just, because I was already stressed about it I just kind of blocked it out kind of thing. It was just easier to do that and then the cost, I just couldn't, so yeah, so when I could have challenged some of those things and me being, would it have even made much difference. (Amal)

Although Amal stopped attending because of financial implications, Alisdair, on the other hand, did not attend one of his hearings because his BASW representative could not attend:

I had no-one to tell me what to do.... and I was quite worried I'd make it worse. (Alisdair)

Although most participants felt they needed representation, not all of them had a good experience when they were represented either by a legal or professional body. For example, Linda felt that some of the advice she received from Unison and her legal representative may have hindered her case as she was advised not to call any witnesses for her hearing. 
Florence, who was represented by BASW, felt that the representative that she had during the day was very good but felt that she received poor advice and support in the lead up to the hearing.

Nevertheless, most participants felt that representation was important, especially during the hearing, and a few wanted to emphasise this in interviews:

I realised that I didn't have a hope in hell to get through this on my own and that I would need legal because they were ripping me apart...the HCPC barrister said that what I did was worse than a burglar or the people that covered up the Hillsborough tragedy. (Ann)

....if you haven't got someone to argue legally for you, you haven't got a chance, and you think it shouldn't be down to money, you know, a system should be, have inbuilt support for both sides really... (Alisdair)

Some felt that legal expertise also prevented registrants from becoming too emotionally involved and thus compromising the hearing. For example, Liam said:

I would have been too, still too angry, and if I'd had to deal with it myself...and so it was really important that I got someone to deal, to stand between me and them [the organisation] because otherwise I would have been unfocussed.....(Liam)

\section{FTP Panel's Knowledge of Social Work}

Three of our participants questioned the FTP Panel's knowledge of social work. For example, when Alisdair tried to demonstrate that he had kept up with his practice knowledge by attending a Community Care Live event, a well-known and established social work conference, 'no-one [on the FTP panel] seemed to know what the Community Care Live event was'.

Similarly, Ann, who implied that the social work member of the panel was long past retirement age, felt:

..the panel did not appear to understand what social workers did, they didn't even understand what a contact centre was .... you feel you're being judged by people that really have no clue of what we're dealing with day to day.... (Ann)

\section{Mea Culpa}

Most of our participants were of the view that HCPC panels preferred registrants to acknowledge fault for the 'mistakes' that had been made:

What they want is for you to go there and say 'I'm sorry. I won't do it again'. (Ann) 
Some participants were of the view that if they argued against the points raised in the referral, for example by claiming that workload pressures led to the errors that were made, they were accused of being 'in denial'. This argument reflects a point raised recently in a Community Care article which reported on the findings of a HCPC case. It was noted that workload pressures were the registrant's responsibility, and even though the HCPC panel acknowledged 'systemic failings' were present in the Local Authority the registrant's suspension was only lifted once she accepted she was still at fault (Stevenson, 2016a).

\section{Referral as Policy}

According to some of our participants it appeared to be local authority policy to refer all concerns resulting in internal disciplinary procedures to the HCPC. According to Ann, in her local authority 'it is their policy for anybody who's been dismissed, no matter for what, they refer to the HCPC'.

Megan, suggested that this policy of referring everything was due to the Local Authority 'lacking confidence in their own abilities'.

.... I don't think they understand how to manage people hence why it was a very oppressive way of managing and, and I just think they just said 'Oh well, send it over to the HCPC, they'll deal with it'. (Megan)

Also highlighted was a lack of information /communication during the period from either being suspended from work and/or referral to the HCPC. Whilst aware of the likely reason behind the referral in general terms there was often a gap before the more detailed allegations were made available to the registrant. Megan expressed her frustration at the lack of information coming from the HCPC. Whilst she recognized that the HCPC was waiting for information from her organisation what she could not understand is why they made no attempt to chase the local authority to provide this:

...I said 'Can't you, you know, like chase this up? This is my professional livelihood, it's my life' and at that point I was, I mean I'd, I'd actually attempted suicide.... (Megan)

Daniel had a similar experience where it was the local authority rather than the HCPC responsible for delaying the process:

...when I got the pack that the HCPC sent, there were at least six communications with the local authority that had remained unanswered, they hadn't sent the stuff that HCPC needed to complete the investigation... (Daniel)

\section{Emotional Costs}

What was apparent from all of the interviews was that the HCPC process invoked considerable emotional stress for all participants involved. The following extracts provide 
some context of the sudden shift in reality that participants experience once they learn they have been referred to the HCPC:

It was [laughs], I was like, I couldn't believe it, it was like waking up to a nightmare... (Amal)

The high emotional cost of the process also had a physical effect on some of our participants:

...I was done, I was broken, I was absolutely broken (Florence)

...it's had an impact, especially with my lupus it's, because stress triggers and yeah, quite ill, quite, it's had a really big impact emotionally, mentally, health wise and obviously financially as well... (Amal)

These negative effects on our participants' health were exacerbated by the length of time the proceedings took, with some of our respondents engaged in processes lasting over two years. The cumulative effect the stress of the process creates clearly has a major impact, a factor that all participants felt required considerable fortitude:

Anybody, anybody weaker would have thrown themselves under a train... (Florence)

Furthermore, of the eight respondents interviewed, five informed us that they had either attempted suicide or had suicidal thoughts.

... I knew it would be a public hearing and I had got it into my head that all my colleagues would be there and I didn't want, I got frightened, don't know why, that was paranoia because all that time I was so stressed, this is the bit that gets hard [starts to cry], I was suicidal, I was suicidal. (Florence)

I became depressed very, very quickly and... I just didn't know what to do. I was, I was just bereft really... This is my, this is my professional livelihood, it's my life and at that point I was, I mean I'd, I'd actually attempted suicide... (Megan)

Although they did survive this process few emerged unscathed. One especially wanted to leave the profession far behind:

... I never wanted to be a social worker ever again, ever, ever. (Florence)

Although some did return to social work few forgot the experience they had been through. The fear of making another 'mistake' was a common theme and led to defensive techniques being implemented or to participants changing role completely:

I probably never will get over it because I'm always terrified if I step out of line or do something wrong that is, that my manager, is going to report me to the HCPC again because I know I could never go through that again. (Florence) 
...I can't do frontline work now.. and in part that's why I asked to do that

[professional development] role because I need to step away from frontline....I'm

still terrified of making a mistake. (Megan)

\section{Discussion}

From the interview data, it is evident that all our participants became involved in the HCPC process because they had experienced some form of conflict with management from within their organisation. Although all of our participants have said they attempted to resolve the issues they encountered internally, it would seem that communication broke down between both parties and as a result the participants were either referred to, or made a self-referral to, the HCPC. This was something noted previously by Furness (2015), who has argued that some employers appear to be more inclined to formalise concerns via the misconduct process rather than attempting to resolve them themselves.

However, what is also of interest, is how two participants welcomed the involvement of the HCPC and sought to use the hearing as a form of recourse to address and expose the organisational and management problems they encountered. Both of these participants wanted the opportunity to demonstrate to the regulator that the issues lay with the organisation and not their own practice. Nonetheless, to prove this was the case they incurred significant financial cost. This suggests that there is a clear imbalance here in terms of financial loss, with the HCPC being able to afford legal costs, ironically from the fees of its registrants, whereas some of our participants could not. Without legal representation, some participants disengaged with the process which culminated with the social worker being struck off. However, while all participants were fully aware of the financial costs they would face they were not prepared for the impact of the emotional turmoil they would also encounter.

Six of our participants felt their problems escalated once the referral to the HCPC was made. This is in part because they feared losing their professional identity, credibility and career for which they had worked hard. Some of these feelings can perhaps be understood from a professional identity perspective where, through the process of professionalization, social workers significantly identify with the role of being a 'social worker', therefore, when this role is denied them, they experience a sense of loss and grief (Leigh, 2013). In addition, in many cases, social workers also experienced a sense of being left in the dark, not sure, in some cases, of why a referral had even been made. This period of not knowing what the future held, coupled with isolation and a lack of support from the HCPC and their own organisation, led many of our participants to contemplate or attempt suicide. From the respondents' narratives little consideration seems to have been given to the employers' 'duty of care' in such instances.

Several of the respondents talked of the actions of their employers in referring them on to the HCPC apparently in lieu of following internal disciplinary procedures. It is interesting to reflect on the key principles that ACAS propose in their disciplinary and grievance code of 
practice, guidance that can be taken into account by Employment Tribunals when determining whether employers have acted fairly. The guidance talks primarily of the need for fairness, timeliness (avoiding 'unreasonable delay') and affording opportunities for employees to be informed of the case and give them an opportunity have their say (ACAS 2015). A significant difference between Employment Tribunals and the HCPC process is the ability of the former to award costs against the employers - as well as the employee.

A common theme to emerge from all the interviews was the time it took for the HCPC to gather its evidence. This meant that those participants who were without work faced financial difficulties, a situation exacerbated for those without a working partner or spouse to support them during this time. Yet we have learned that even when the hearing is over and a decision reached this does not necessarily mean that the ordeal is over for the referred social worker. Many talked of experiencing ongoing and debilitating stress that either left them feeling paranoid that this would happen again or meant they felt unable to return to social work. With the profession struggling to maintain morale and retain experienced practitioners (McFadden et al. 2015), this is a major concern.

\section{Conclusion}

Our research suggests that we currently have a regulatory system in place that positions social workers at a disadvantage and which raises several ethical and moral issues in relation to power, representation, fairness and finance. While we appreciate that this study only involved a small group of social workers, our data has still nonetheless raised questions about the regulatory process to which social workers are subject.

First, it is evident that those who are removed suddenly from their post and then have to wait a long time for the HCPC process to conclude, experience significant emotional distress about what the future may hold. Whilst we accept that the HCPC is in a difficult position in cases such as these, we also recognize that it is still a powerful regulatory body. As a result, the HCPC is in a position to exert more pressure on referring organisations to provide the required information for proceedings to be expedited in a more timely manner.

Second, it has become apparent that whilst registrants are waiting to go through the process they experience feelings of distress, marginalisation and isolation. If registrants were able to access more support, not only from the HCPC and their own organisation, but also from having the opportunity to contact other registrants who are in a similar position it would help them significantly. An advice/support group could be created by linking social workers to an online network which registrants could join on a voluntarily basis.

Third, it is evident that the financial losses registrants face as a result of employing legal representation has substantial implications. These not only affect their livelihoods but also led some to disengage with the HCPC process altogether. Nevertheless, many of our participants still felt it was needed not only in terms of legal expertise but also for emotional or general supportive reasons. In addition, appeals against the FTP panel's decision have to be made to the High Court in England within 28 days of the date of the original notice, a 'formal' right that, given the expenses involved, in effect leaves many social workers with little recourse against what they believe to be an unfavourable FTP outcome. 
To practise as a social worker, social workers must pay to be registered with the HCPC with their registration fees used by the HCPC to pursue cases against them. If these fees were also made available for social workers to contract appropriate legal representation, a more level playing field could be established financially.

Recently, there have been reports that the HCPC may lose its role as the regulator of social workers with an announcement that a new social work specific body is to replace it (Stevenson, 2016b). Although it is too early to tell if or when this will happen we strongly recommend that the findings from this paper, and previous papers into the HCPC process, are given careful consideration in informing the structure and direction of any new regulatory system. 


\section{$\underline{\text { References }}$}

ACAS (2015) (Advisory, Conciliation and Arbitration Service) Code of Practice on Disciplinary and Grievance Procedures. Norwich: The Stationary Office.

Braun, V. \& Clarke, V. (2006) Using thematic analysis in Psychology, Qualitative Research in Psychology, 3, pp.77-101

Bryman, A. (2004) Social Research Methods (2nd Edition). Oxford: Oxford University Press

Chase, S.E. (2008) 'Narrative inquiry: multiple lenses, approaches, voices', in N. Denzin and Y. Lincoln (eds), Collecting and Interpreting Qualitative Materials, Thousand Oaks, CA: SAGE

Corbin, J.M. \& Strauss, A.L. (2008) Basics of Qualitative Research: Techniques and procedures for developing grounded theory: $3^{\text {rd }}$ edition. Thousand Oaks, California: Sage

Elliott, J. (2005) Using narrative in social research: qualitative and quantitative approaches. London: Sage

Evans, C. \& Jones, R. (2004) 'Engagement and empowerment, research and relevance: comments on user-controlled research', Research Policy and Planning, vol.22, pp. 5-14.

Furness, S. (2015) 'Conduct Matters: The regulation of social work in England', British Journal of Social Work, vol.45, pp.861-879.

Hardwick, L. \& Worsley, A. (2011) Doing Social Work Research, London: Sage

HCPC (2011) (Health and Social Care Processions Council) 'Indicative Sanctions Policy', http://www.hpc-uk.org/assets/documents/10000A9CPractice Note Sanctions.pdf (accessed 29/4/16)

HCPC (Health and Care Professions Council) (2012a) 'Prosecution Policy', London: HCPC http://www.hpc-uk.org/assets/documents/10003FB5POLICY-Prosecutions-Aug2012.pdf (accessed 27/5/16)

HCPC (Health and Care Professions Council) (2012b) 'Practice Note: Finding that practice is "impaired"', London: HCPC http://www.hcpc-

uk.org.uk/assets/documents/1000289FFindingthatFitnesstoPractiseis/mpaired.pdf (accessed 27/4/16)

HCPC (Health and Care Professions Council) (2013) 'Fitness to Practise Annual Report 2013', London, HCPC 
http://www.hcpcuk.org/assets/documents/100042D7Fitnesstopractiseannualreport2013.p df (accessed 1/4/14)

HCPC (Health and Care Professions Council) (2015) 'Fitness to Practise Annual Report 2015', London: HCPC http://www.hpc-

uk.org/assets/documents/10004E22Fitnesstopractiseannualreport2015.pdf (accessed $11 / 5 / 16)$

Holliday, A. (2007) Doing and Writing Qualitative Research ( $2^{\text {nd }}$ ed.), London: Sage

Leigh, J. (2013) 'The Process of Professionalization: Exploring the identities of child protection social worker', Journal of Social Work. Published online 7th October, 2013.

Leigh, J. (2014) 'The story of the PPO Queen: the acceptance and development of a spoiled identity', Child and Family Social Work. 26 May 2014.

Lofland, J. \& Lofland, L. H. (1984) Analysing Social Settings: a guide to qualitative observation and analysis, $2^{\text {nd }}$ ed. Belmot, Cal.: Wadsworth

Mcfadden, P., Campbell, A., Taylor, B. (2015) Resilience and burnout in child protection social work: Individual and Organisational Themes from a Systematic Literature Review. British Journal of Social Work, 2015, Vol. 45, pp.1546-1563.

Mishler, E.G. (2005) 'Patient stories, narratives of resistance and the ethics of humane care: à la recherche du temps perdu', An Interdisciplinary Journal for the Social Study of Health Illness and Medicine, vol. 9, pp. 431-451.

Narey, M. (2014) Making the education of social workers consistently effective. Department of Education: London. Accessed $9^{\text {th }}$ of May 2016:

https://www.gov.uk/government/publications/making-the-education-of-social-workersconsistently-effective

Platt, J. (1998) 'What can case studies do?' in R.G. Burgess (ed.) Studies in Qualitative Methodology vol.1, Greenwood, CT: JAI Press, pp. 1-23

Robson, C. (1998) 'Real World Research: a resource for social scientists and practitioner researchers', Oxford: Blackwells.

Schraer, R. (2014) 'HCPC under attack over claimed breaches of social workers' human rights', Community Care (accessed 9/5/16)

http://www.communitycare.co.uk/2014/12/09/hcpc-attack-claimed-breaches-socialworkers-human-rights/

Stevenson, L. (2016a) Social worker's suspension lifted after accepting workload pressures were 'her responsibility'. Community Care (accessed 9/5/16) 
http://www.communitycare.co.uk/2016/03/16/social-workers-suspension-lifted-acceptingworkload-pressures-responsibility/

Stevenson, L. (2016b) New body to take responsibility for social work standards and regulation. Community Care (accessed 9/5/16)

http://www.communitycare.co.uk/2016/01/14/new-body-take-responsibility-social-workstandards-regulation/ 